\title{
Romper comunidad, crear comunidad: historias de la excomunión y conjetura democrática
}

\author{
Break community, create community. Excommunication
}

stories and democratic conjecture

DIEGO TATIÁN ${ }^{a}$

\section{Resumen}

El presente trabajo indaga las condiciones históricas e ideológicas de la excomunión de Spinoza en 1656, y la vinculación de este episodio con las discutidas influencias de Van den Enden, Juan de Prado o Isaac la Peyrère en la temprana heterodoxia del joven Baruch, según las clásicas tesis de investigadores como Madelaine Francès, I. S. Rèvah, Jacob Teicher, Carl Gebhardt o, más recientemente, Richard Popkin, Josef Kaplan y Steven Nadler. A partir de este relevamiento historiográfico se sugiere una motivación "democrática" en el fondo de la segregación de Spinoza por la Sinagoga y su puesta fuera de comunidad.

Palabras clave: Spinoza. Excomunión. Democracia.

\begin{abstract}
The present article investigates the historical and ideological conditions of Spinoza's excommunication in 1656, and the linking of this episode with the discussed influences of Van den Enden, Juan de Prado or Isaac la Peyrère in the early heterodoxy of the young Baruch, according to the classic thesis of researchers such as Madelaine Francès, I. S. Rèvah, Jacob Teicher, Carl Gebhardt or, more recently, Richard Popkin, Josef Kaplan and Steven Nadler. Based on this historiographic research, a "democratic" motivation is suggested in the background of the segregation of Spinoza by the Synagogue and its placing outside the community.

Keywords: Spinoza. Excommunication. Democracy.

a Universidad Nacional de Córdoba, Córdoba, Argentina. Doctor en Filosofía, e-mail: diegotatian@gmail.com
\end{abstract}


Casi con seguridad, siendo un niño de ocho años, Baruch Spinoza se encontraba en la Sinagoga de Ámsterdam la tarde de 1640 en la que Uriel da Costa recibió, allí mismo y delante de todos, "cuarenta azotes menos uno" como establece la Ley. Da Costa había sido un "cristiano nuevo" en Oporto y llegaría a Ámsterdam en 1612, legatario de la conmovedora y trágica historia de los marranos que, finalmente, habían encontrado en Holanda un lugar para retornar al judaísmo que debieron conservar en secreto durante más de un siglo.

La humillación pública de Uriel (a la que aceptó someterse por desesperación) es relatada por él mismo en un texto estremecedor que se conoce bajo el título de Espejo de una vida humana, antes de acabar con su vida por mano propia. Se lee allí: "Entré en la Sinagoga, llena de hombres y mujeres que habían venido como para un espectáculo... Acto seguido, llegó un sayón, tomó unas correas y me propinó en la espalda treinta y nueve azotes, según es tradición... Entre azote y azote cantaban salmos... Luego tomé mis ropas y me postré en el umbral de la Sinagoga, y un custodio sostenía mi cabeza. Todos los que salían pasaban sobre mí, levantando un pie por encima de la parte inferior de mis piernas; y esto hicieron todos, así niños como ancianos"1.

Es muy probable que el pequeño Baruch haya sido uno de esos niños. Dieciséis años más tarde, él mismo sería excomulgado por "terribles herejías" y "actos onstruosos", según consta en el herem (palabra cuya más antigua acepción veterotestamentaria es “aniquilación”) que lo ponía fuera de la comunidad, sin duda el más extremo y virulento de todos los que tuvieron lugar en la Sinagoga amstelodana. En ese momento Spinoza contaba con veinticuatro años y aún no había escrito nada, pues la redacción su primer texto no es anterior a 1657-8.

¿Cuáles eran, pues, esas terribles herejías y esos actos monstruosos que merecieron las impresionantes maldiciones del herem ("Maldito sea de día y maldito sea de noche, maldito al acostarse y maldito al levantarse, maldito sea al entrar y al

\footnotetext{
${ }^{1}$ Uriel da Costa, Espejo de una vida humana, edición de Gabriel Albiac, Hiperión, Madrid, 1985, p. 41. Rev. Filos., Aurora, Curitiba, v. 32, n. 56, p. 365-384, maio/ago. 2020
} 
salir..."2)? Se trata de uno de los grandes misterios del spinozismo. Seguramente, como señalaba el viejo relato biográfico de J. Segond ${ }^{3}$, la intensidad de la excomunión contra Spinoza guarda proporción con las expectativas que el joven Baruch ("discípulo predilecto del viejo Morteira") había despertado en las autoridades rabínicas como estudioso de la Ley. Spinoza era tal vez la mayor esperanza de la comunidad y el más agudo lector del Libro Sagrado entre todos los estudiantes formados en la escuela Talmud Torá y en la yeshivá Keter Torá; no era un escolar cualquiera.

La fuente más antigua con la que contamos es el relato del médico francés JeanMaximilien Lucas, quien atribuye la excomunión a una delación y al "odio" consiguiente de su maestro Morteira. Se trata de la leyenda negra de la excomunión de Spinoza, de la que Lucas extrae la clásica conclusión libertina: "los eclesiásticos, cualquiera sea su religión -gentiles, judíos, cristianos, mahometanos-, son más celosos de su autoridad que de la justicia y la verdad, y están todos animados por el mismo espíritu de persecución". Como quiera que sea, en 1656 -aunque no escritas aúnSpinoza seguramente tenía ya muchas de las ideas que alcanzarían pleno desarrollo filosófico en sus obras mayores: origen puramente humano y no divino de la Biblia; eternidad y divinidad del mundo; denuncia del empleo político de las religiones, y del miedo y la esperanza referidos a la vida después de la muerte; negación de la inmortalidad del alma; inexistencia de un Dios que castiga y premia...

Mucho se ha especulado sobre el origen de la "corrupción" de Spinoza. Unos creen hallarlo en las tendencias heterodoxas de la propia comunidad sefaradita de Ámsterdam, o bien en algunos autores clásicos del pensamiento judío medioeval como Ibn Esra (quien en el siglo XII escribió: "Dios está en todo y todo está en él”), Flavio Josefo, Gersónides, Filón de Alejandría, Jehudá Alfakar, Maimónides o -tal vez la mayor influencia de un filósofo judío sobre el spinozismo- Hasdai Crescas. Asimismo, en un autor fundamental del judaísmo neoplatónico renacentista como Judah

\footnotetext{
${ }^{2}$ Atilano Domínguez (comp.), Biografías de Spinoza, Alianza, Madrid, 1995, p. 187.

${ }^{3}$ Jules Segond, La vie de Benoît de Spinoza, Librairie Académique Perrin Éditeur, Paris, 1933, pp. 67 y ss.
} 
Abrabanel (mejor conocido como León $\mathrm{Hebreo}^{4}$ ), o incluso en Joseph Delmedigo ${ }^{5} \mathrm{y}$ otros filósofos judíos de la baja Edad Media y el Renacimiento que habrían impregnado los medios marranos con algunas tesis averroístas tales como la eternidad del mundo, la eternidad del alma o la denuncia de Moisés, Cristo y Mahoma como grandes impostores. Por su parte Richard Popkin ${ }^{6}$ adjudica al misterioso Isaac La Peyrère -y en particular a su libro Prae-Adamitae (1655), que Spinoza tenía en su biblioteca- un lugar fundamental en la formación de la herejía spinozista. La Peyrère era amigo de Menasseh ben Israel, vivió un tiempo en Ámsterdam justo antes de la excomunión y no es imposible que el joven Baruch haya entrado en contacto con él a través de su maestro.

En esta abigarrada trama de conjeturas con la que se busca comprender un punto de quiebre -que seguramente no es un punto- no resulta inesencial la pregunta por la lengua. ¿Es el acceso a la lengua latina relevante para comprender la ruptura spinozista, o al revés, es la ruptura la que lleva al joven filósofo a aprender latín con un viejo lucianista que había sido jesuita en su juventud y un esprit fort en su madurez? Algunos estudiosos como Madelaine Francès ${ }^{7}$, Theun de Vries ${ }^{8}$ o más recientemente Wim Klever creen efectivamente haber visto el nacimiento de la "herejía" spinozista en el taller de Francis van den Enden, libre pensador que años más tarde acabaría colgado en la Bastilla por atentar contra el Rey de Francia. A la escuela de Van den Enden asistía Spinoza (entre otros

${ }^{4}$ En la biblioteca de Spinoza consta una edición castellana de los Dialoghi d'Amore; según Carl Gebhardt, fue esta obra lo que condujo al joven Spinoza a la ruptura con la Sinagoga, a la idea de Deus sive Natura, y en general hacia las fuentes vitales de la filosofía europea.

${ }^{5}$ Médico, rabino, discípulo de Galileo en Padua, Joseph Salomon Delmedigo llegó a Ámsterdam en 1626 y tuvo estrecho vínculo con Menasseh ben Israel, quien publicó en su imprenta algunos escritos de Delmedigo (entre otros, uno de divulgación de las teorías científicas galileanas Ilamado Sefer Elim, que se encontraba en la biblioteca de Spinoza) -J. d'Ancona, quien fuera rabino de Ámsterdam antes de ser asesinado en los campos nazis de Polonia, sostuvo en su libro Delmedigo, Menasseh ben Israel y Spinoza (1940) que la fuente principal del Tratado breve es el Sefer Elim (cfr. Levy Ze'ev, "Sur quelques influences juives dans le developpement philosophique du jeune Spinoza", en Revue des Sciences philosophiques et théologiques, 71, 1/1987, pp. 67-76).

${ }^{6}$ Richard Popkin, "The Marrano Theology of Isaac La Peyrère", en Studi Internazionali di Filosofia, n 5, 1973; también Isaac La Peyrère, 1596-1676, Brill, Leiden, 1987.

${ }^{7}$ Madeleine Francès, Spinoza dans les pays néerlandais de la seconde moitié du XVIle siècle, Alcan, Paris, 1937.

${ }^{8}$ Theun de Vries, Baruch Spinoza. Mil Selbstzeugnissen und Bilddokumenten, Rowohlt, Hamburg, 1970. 
jóvenes de familias ilustradas, como tal vez el propio Rembrandt) a estudiar latín. Pero no era sólo latín lo que el inquieto Baruch pudo aprender en casa del maestro libertino; además de los clásicos latinos (Séneca, Salustio, Terencio...), allí habría conocido los grandes textos de la tradición atomista, el epicureísmo romano, las obras de Vanini, Maquiavelo y Hobbes. La frecuentación de Van den Enden -con quien Spinoza había aprendido a considerar a la filosofía por encima de la Torah- habría molestado a los parnasim de la comunidad, los que, tras advertirlo en vano, tomarían la drástica decisión del herem 9 .

Por su parte Meinsma -en su clásico estudio sobre el círculo spinozista ${ }^{10}$ atribuye el principal motivo de la ruptura al vínculo con los colegiantes (De Vries, Jelles, Rieuwertsz, Boreel, Balling...) que se estima data de 1654. Con el herem, la Sinagoga habría querido mostrar la inadmisibilidad de cartesianos en su seno, en sintonía con el clima anticartesiano que sacudía los medios religiosos y las universidades holandesas (cuyo centro era la Universidad de Utrecht y su principal impulsor el teólogo gomarista Gisbertus Voetius).

Más recientemente se ha considerado que la razón principal del conflicto entre el joven Baruch y su comunidad no fue de orden religioso ni filosófico sino financiero. Para librarse de las deudas heredadas de su padre (que había muerto en 1654), Baruch recurrió al amparo de una ley holandesa que protegía a los menores de edad (según la legislación vigente lo eran todos los menores de 25 años) que habían quedado huérfanos, adjudicándoseles un tutor hasta su mayoría de edad. En 1655 el orfanato de Ámsterdam designa a Louis Crayer (que tras la muerte del pintor sería asimismo tutor de Titus

\footnotetext{
${ }^{9}$ No resultaría inapropiada la conjetura de un vínculo entre excomunión y maquiavelismo. Y. Kaplan y Y. H. Yerushalmi han mostrado que el adjetivo "maquiavelista" era empleado en la comunidad judía amstelodana para designar a los ateos y a los espíritus antirreligiosos en general, y han identificado en el pensamiento político español del siglo XVII la fuente -no suficientemente estudiada- del extendido antimaquiavelismo en la diáspora sefaradí y entre los intelectuales judíos de Ámsterdam. Si bien no existen indicios de un maquiavelismo explícito en el joven Spinoza -que será manifiesto en el Tratado político y algo más reticente en la Ética- es posible que por mediación de Van den Enden haya habido una temprana apropiación del pensamiento político maquiaveliano por Spinoza, y que esa apropiación no haya estado ausente entre los motivos del herem. (Sobre la influencia del pensamiento cristiano español en la comunidad sefaradita de Ámsterdam, ver Y. Kaplan, Judíos nuevos en Ámsterdam, Gedisa, Barcelona, 1996, pp.57-60).

${ }^{10}$ Spinoza et son cercle, Vrin, Paris, 1983.
} 
Rembrandt) a cargo de Spinoza11, con lo que su hermano Gabriel -quien en 1664 se embarcaría hacia Barbados, como su hermana Rebeca lo había hecho hacia Curaçao, donde murió de fiebre amarilla en 1695- debió afrontar las deudas pendientes del negocio paterno (“ ¿no fue este -se pregunta Méchoulan- un primer paso fuera de la comunidad...?”12).

Todos estos elementos, sin ser irrelevantes, serían insuficientes por sí mismos. O quizá se haga necesario considerar todo a la vez, según sostiene Steven Nadler en la última biografía de Spinoza: "Ex jesuitas de ideas políticas avanzadas, colegiantes de tendencias socinianas, judíos apóstatas, cuáqueros y libertinos libre pensadores: si se trata de buscar el 'corruptor' de Spinoza, entonces, en un sentido, el verdadero culpable es la misma Ámsterdam”"13.

Pero no bastaba una herejía cauta y aún ágrafa -que además no habrá sido única, y ni siquiera rara- para un anatema como el berem a Spinoza, cuya violencia fue mayor a la de cualquier otro, antes o después de su caso. En una conferencia de 1957 leída en la Universidad de Cambridge (publicada dos años más tarde por León Dujovne en la revista Davar de Buenos Aires ${ }^{14}$ ), el profesor Jacob Teicher establece una hipótesis al respecto ${ }^{15}$.

${ }^{11}$ Cfr. A. M. Vaz Dias y W. G. van der Tak, Spinoza, mercator et autodidactus, Martinus Nijhoff, Den Haag, 1933.

${ }^{12}$ Henri Méchoulan, "Le herem à Ámsterdam et 'I'excommunication' de Spinoza", en Cahiers Spinoza, 3, Réplique, Paris, 1979-80, p. 127 [también Steven Nadler, Spinoza, Acento, Madrid, 2004, p. 172].

${ }^{13}$ Steven Nadler, cit., p. 206.

${ }^{14}$ En el primer tomo de su Spinoza (Universidad de Buenos Aires, 4 vol., 1940-1944, pp. $101-$ 125) Dujovne había basado su interpretación de la excomunión en las investigaciones de Gebhardt sobre Juan de Prado (Chronicon Spinozanum, tomo III, 1923, pp. 263-291), y a partir de un pasaje de la Epístola invectiva de Orobio de Castro sostienía que "...la primera rebeldía de Spinoza pudo nacer entre sofistas judíos y no entre libertinos cristianos". Sin embargo, la excomunión no se habría debido a razones religiosas o filosóficas, sino a conductas y "actos" como burlarse de las fórmulas del culto e incumplimiento de las prescripciones establecidas por la Sinagoga. En línea con la posición gebhardtiana, el spinozista argentino escribía: “...si prescindimos de las fórmulas prácticas del lenguaje, no podemos dejar de reconocer que la comunidad tenía razón. Su deber era organizar un judaísmo fiel a la Ley y de ninguna manera podía permitir que los jóvenes, siguiendo el camino de Juan de Prado, se crearan su propia religión; religión que sustituiría la revelación por la Razón, buscaba a Dios en la Naturaleza y solo reconocía como leyes divinas las leyes de la Naturaleza". La comunidad, en efecto, "no debía responsabilizarse por un hombre como Spinoza".

${ }^{15}$ Jacob L. Teicher, "Why was Spinoza banned?", in The Menorah Journal, vol. XI, V (1957), pp. 41-60. 
Según documentos y cartas hallados por él, en 1636 se produjo una intensa disputa entre los miembros rabínicos de la comunidad de Ámsterdam. La controversia se refería a una cuestión teológica: si el castigo después de la muerte por graves pecados cometidos en la vida terrenal -como los de apostasía y herejía- era eterno o no. La disputa alcanzó tal dimensión que los dirigentes de la comunidad creyeron conveniente someterla a un fallo del tribunal rabínico de Venecia, a resultas de lo cual se ordena desistir de su tesis a los no eternalistas (quienes no sólo negaban la eternidad del castigo sino que incluso llegaban a sostener que Dios, en su infinita misericordia, salvará también a los cristianos).

Los eternalistas a su vez (que tenían sus mayores exponentes en Saúl Levi Morteira y Menasseh ben Israel, maestros de Spinoza) sostenían que si la creencia en la eternidad del castigo era abandonada, ello tendría efectos desastrosos entre los marranos de España y Portugal, que no arriesgarían sus vidas emigrando para mantener su fe. Menasseh sostiene además que si los cristianos llegaban a saber que los judíos rechazan el castigo eterno de los pecados graves, sostendrían que los hijos de Israel no distinguen entre el justo y el pecador y que no temen a Dios. En el fondo, el peligro no tendría que ver con que los cristianos tuvieran una "opinión desfavorable" de los judíos, sino con el hecho concreto de que las autoridades tomaran medidas políticas contra ellos.

En efecto, la situación legal de los judíos en Holanda no estaba exenta de vigilancia y condiciones. En 1615, con el objeto de legislar el establecimiento de los judíos, el gobierno de Holanda encargó a Hugo Grocio la redacción de un reglamento sobre esta cuestión; el texto, que se conoce con el nombre de Remonstrantie, fue aprobado en 1619. Allí se lee: “Todos los judíos mayores de edad deben hacer ante el magistrado la siguiente declaración referente a su fe: si creen en un Dios único, creador y rector del universo y origen de todo bien, a quien es obligación honrar, servir y venerar; si Moisés y los Profetas han escrito la verdad bajo la inspiración de Dios; y si existe otra vida después de la muerte en la que el justo será premiado y el pecador castigado”. Poco más adelante se dispone que quien enseñe de manera pública o secreta 
principios opuestos a estas disposiciones, se hará "pasible de la pena de muerte o de otros castigos corporales, conforme la gravedad del delito".

A la luz de este documento, el temor por parte de los rabinos de que las autoridades cristianas tomaran severas medidas contra la aún inestable comunidad judía, parecieran plenamente justificados. Mientras en el resto de Europa los judíos eran perseguidos por serlo, en Holanda serían tolerados sólo si observaban el judaísmo de manera estricta. La Sinagoga de Ámsterdam no habría impuesto sanciones ni excomulgado a los herejes en general sino a aquéllos que entraban en contradicción con el texto de Grocio - como había sido, sin duda, el caso de Uriel da Costa (quien sostenía explícitamente que la ley mosaica no enseña la inmortalidad del alma, ni que hubiera castigos y premios después de la muerte).

Sin embargo, cuando Spinoza fue excomulgado en 1656 las cosas habían cambiado considerablemente y la situación no era la misma que en la fecha de la excomunión de Uriel. Ese mismo año el gobierno de Holanda declaró que "la filosofía es algo enteramente diferente de la teología”, y se estableció, por decreto, que una libertad plena para las indagaciones filosóficas impere en las universidades holandesas. Aunque este decreto es unos meses posterior a la excomunión de Spinoza, es poco probable que las autoridades de la Sinagoga desconocieran la tendencia liberal del gobierno -y de hecho, la excomunión de Juan de Prado, en 1657, tuvo lugar un año después del mismo. Más aún, pocos meses más tarde el gobierno privó a la comunidad judía de excomulgar a sus miembros por herejía -y en efecto, según Teicher después de 1657 no se registran en Ámsterdam excomuniones por motivos religiosos o filosóficos ${ }^{16}$.

Por lo tanto no cabría alegar la Remonstrantie en este caso, pues su texto había quedado prácticamente sin efecto. Al condenar a Spinoza -dice Teicher-, los rabíes de Ámsterdam actuaron en franca oposición con la política liberal del gobierno. Lo cierto

\footnotetext{
${ }^{16}$ Asimismo, Kaplan señala que las excomuniones judías solían ser criticadas por escritores políticos, hombres de letras y teólogos calvinistas; en 1662 Philip van Limborch instaba a las autoridades políticas a tomar medidas contra las sanciones que la comunidad judía imponía a disidentes, adjudicándose una función que únicamente competía al Estado -produciéndose de este modo "una república dentro de una república" (cfr. Y. Kaplan, op. cit., p. 40).
} 
es que la colectividad no quería contar entre sus miembros con deístas o filósofos pero no ya para cuidarse de las autoridades de la ciudad, sino por un motivo político diferente.

Precisamente en los años 1656 y 1657 se produjo en Inglaterra un importante debate sobre la readmisión de los judíos. El propio Menasseh ben Israel viajó a Londres para predisponer a Olivier Cronwell a favor de los judíos, argumentando que los acontecimientos profetizados como anuncios de la llegada del Mesías, habían ya ocurrido casi todos -habida cuenta de la historia relatada por Antonio de Montezinos, quien dijo haber conocido "indios hebreos" en los Andes ${ }^{17}$. Lo único que aún faltaba era la completa dispersión de los judíos por los cuatro rincones del globo, y sólo Inglaterra carecía de ellos. La misión de Menasseh en Londres -que se inscribe en el clima milenarista del momento- era convencer a los ingleses de admitir judíos antes del fin de los tiempos, para lo cual resultaba decisivo mostrar que no había ateos ente ellos. Las de Spinoza y Prado habrían sido, según esta hipótesis, excomuniones políticas que apuntaban hacia Londres ${ }^{18}$.

${ }^{17}$ El aventurero criptojudío portugués Antonio de Montezinos, que había recorrido América durante varios años hasta 1644, se emabarca ese año hacia Ámsterdam donde vive seis meses, antes de volver definitivamente a Pernambuco para morir allí pocos años después. Durante sus meses amstelodanos le asegura a Menasseh ben Israel haber visto en un "pueblo escondido" de los Andes sudamericanos (más precisamente en Nueva Granada, actual Colombia), una tribu indígena que celebraba un oficio religioso judío acompañado de recitaciones en hebreo. Menasseh se convence de que aquella tribu era una de las tribus perdidas de Israel, y en 1650 publica Esperanza de Israel (traducida al inglés ese mismo año y dedicada por el traductor -también milenarista- al Parlamento inglés). Verídica o no, la historia transmitida por Montezinos produjo una intensa efervescencia milenarista en las juderías de Ámsterdam y de Londres, que se extiende hasta 1666, año en el que llega a su cumbre la esperanza de que el Mesías había finalmente llegado y era Sabbatai Zevi (ver el prólogo de Henri Méchoulan a Menasseh ben Israel, Esperanza de Israel, edición de Henry Méchoulan y Gérard Nabon, Hiperión, Madrid, 1987, pp. 69-76).

${ }^{18}$ Otros estudiosos del judaísmo amstelodano -tal el caso de Henri Méchoulan- han negado que la excomunión de Spinoza tuviera algún vínculo con las tratativas ante Cronwell para la readmisión de los judíos en Inglaterra: “...rechazamos absolutamente la hipótesis de un herem querido y organizado para facilitar la tarea de Menasseh ben Israel en Londres... En efecto, el Mahamad de Ámsterdam no tenía ningún interés -como tampoco Menasseh ben Israel- en presentar ante los ojos del mundo cristiano reformado, y en particular ante Cronwell, una comunidad que genera esprits forts" (Henri Méchoulan, cit., p. 132). 
Casi en simultáneo a la conferencia de Teicher, siguiendo la vía abierta en los años 20 por Carl Gebhardt, Israel S. Révah publica el clásico Spinoza et le Dr. Juan de Prado ${ }^{19}$, que motivaría una fecunda discusión en la historiografía referida a la excomunión de Spinoza y la formación del spinozismo. Como resultado de pacientes estudios en los archivos de la Inquisición española, Révah aduce un conjunto de documentos que revelan la existencia de una corriente clandestina de pensamiento heterodoxo entre los judíos de la Península -con centro en la Universidad de Alcalá de Henares- que estaría a la base de la ruptura spinozista. Proveniente precisamente de Alcalá, el médico deísta Juan de Prado (marrano doble, dice Révah: por relación a los cristianos en tanto criptojudío; por relación a los propios marranos en tanto deísta) había llegado a la ciudad de Ámsterdam un año antes de la excomunión de Spinoza, y sería excomulgado él mismo un año después.

Carl Gebhardt había descubierto en 1923 un manuscrito de Orobio de Castro llamado Epistola Invectiva Contra un Judío Philosopho Médico, que Negava la Ley de Mosse, y Siendo Atheista Affectava la Ley de Naturaleza [en otra versión Epistola Invectiva Contra Prado, un Philosopho Medico, que Dubitava, o no Creya la Verdad de la Divina Escritura, y Pretendió Encubrir su Malicia con la Affecta Confacion de Dios, y Ley de Natureza], escrito probablemente en 1663 ó 1664, en el que encuentra vestigios del influjo de Prado sobre el joven filósofo (más de 20 años menor que él), que desembocaría finalmente en su excomunión. Gebhardt y Révah afirman que para los judíos amstelodanos contemporáneos a ellas, las excomuniones de Spinoza y Prado constituyen un mismo evento.

Luego de las excomuniones (en 1656 y 1657 respectivamente), se pierden las huellas de Spinoza y Prado en Ámsterdam. Por azar, Révah descubre en 1955, en los Archivos de la Inquisición, dos documentos que suministran algunas informaciones sobre esas huellas. Se trata del informe del monje agustiniano Fray Tomás Solano y Robles, originario de la actual Colombia, quien había vivido en Ámsterdam entre agosto

\footnotetext{
${ }^{19}$ Israel Révah, Spinoza et le Dr. Juan de Prado, Mouton, Paris, 1959. Publicado más recientemente en I. S. Révah, Des marranes a Spinoza, textos reunidos por Henri Mechoulan, Pierre-François Moreau y Carsten Lorenz Wilke, Vrin, Paris, 1995.
} 
de 1658 y marzo de 1659; y la presentación ante el inquisidor de Madrid en agosto de 1659 del Capitán Miguel Pérez de Maltranilla, quien vivió en Ámsterdam entre noviembre de 1658 y enero de 1659, en la misma casa en la que habitaba Fray Tomás. Según Maltranilla, en 1658-59 Prado y Spinoza se frecuentaban y formaban parte de una tertulia en casa de Joseph Guerra, junto al Dr. Reynoso (médico sevillano) y otro sevillano llamado Pacheco ${ }^{20}$. Hasta el momento de mudarse a Rijnsburg en 1660, sostiene Révah, Spinoza mantiene su vínculo con Prado, y ambos forman parte de un mismo círculo "deísta". Los testimonios del fraile y el capitán completarían la argumentación de M. Francès y permitirían desechar, según su descuibridor, la por él llamada "hipótesis colegiante".

La historia de Fray Tomás y la de Montezinos constituyen episodios de lo que Sebastián Pineda Buitrago llama el factor "ladinoamericano" en el origen del spinozismo ${ }^{21}$. Natural de Tunja, muy cerca de Bogotá, Fray Tomás Solano y Robles se había embarcado en Venezuela hacia Roma para ordenarse como sacerdote, pero fue secuestrado en altamar por piratas ingleses y luego encarcelado en Londres. Una vez recuperada la libertad se trasladó a Ámsterdam²2, donde se incorporó a las tertulias

${ }^{20}$ Otra importante información obtenida de estos documentos es que en el año académico 1658-9 Spinoza era estudiante de filosofía en Leiden como "oyente libre". Estos estudios en Leiden permitirían explicar su traslado a Rijnsburg (ciudad que se hallaba más próxima a la de Leiden) hacia 1660.

${ }^{21}$ Sebastián Pineda Buitrago, "Baruch Spinoza y América Ladina: En busca del fraile colombiano 'delator' de Spinoza y del factor hispánico en el origen de la filosofía moderna" [http://www.istor.cide.edu/archivos/num_42/notas.pdf].

${ }^{22}$ El vínculo entre los judíos de Londres y los de Ámsterdam era estrecho, sobre todo debido a intereses comerciales comunes. Uno de los socios principales en Ámsterdam de Antonio Fernández de Carvajal, importante referente sefardí de Londres, era Miguel Espinosa, padre del filósofo. Sus redes comerciales se extendían hasta los ingenios azucareros de las Canarias, de la isla británica de Barbados y hasta la colonia holandesa en Recife (donde vivían 5000 judíos holandeses -entre ellos Isaac Aboab, futuro lector del anatema contra Spinoza). El contacto con América fue intenso hasta que el imperio holandés perdió sus posesiones coloniales en Brasil en 1654, cuando Pernambuco fue recuperado por Portugal. Ese mismo año de 1654 falleció en Ámsterdam Miguel Espinosa. Baruch había heredado de su padre, junto con su hermano Gabriel, los negocios y las rutas comerciales. Ambos habían fundado la compañía comercial Bento et Gabriel D’Espinosa para la importación y exportación de frutos secos y caña de azúcar. Esos productos venían naturalmente del Sur, de Canarias, del Caribe, de Suramérica (cfr. ibid.). Y ese mismo año, según consta en los archivos de la Nação, Baruch 
libertinas de las que también participaban Spinoza, Prado y otros deístas o ateos judeopeninsulares. En un pasaje de su declaración, afirma Fray Tomás "que conoció al Dr. Prado, médico que se llamaba Juan y no sabe qué nombre tenía de Judío, que había estudiado en Alcalá, y a un fulano de Espinosa que entiende era general de una de las ciudades de Holanda porque había estudiado en Leiden y era buen filósofo; los cuales profesaban la ley de Moisés y la Sinagoga los había expelido y apartado de ella por haber dado en ateístas; y ellos mismos le dijeron a éste que estaban circuncidados y guardaban la ley de los Judíos, y que ellos mismos habían mudado de opinión por parecerles que no era verdadera la dicha Ley y que las almas morían con los cuerpos, no había Dios sino filosofalmente y que por eso los había echado de la Sinagoga; y, aunque sentían las faltas de las limosnas que les daban en la Sinagoga y la comunicación con los demás Judíos contentos con tener el error del ateísmo, porque sentían que no había Dios sino es filosofalmente (como ha declarado) y que las almas morían con el cuerpo y así no había menester fe $[\ldots]^{23}$.

De modo que, según Révah, las tres ideas deístas por las que Spinoza fue excomulgado (las almas mueren con el cuerpo; Dios no existe más que en sentido filosófico; la fe es inútil) concilian con las enseñanzas de Prado (y de Uriel) y no con la religiosidad colegiante ni con la metafísica de Descartes. Spinoza y Prado habrían sido excomulgados por “filósofos” y por deístas ${ }^{24}$.

La tesis de Révah ha sido discutida por algunos investigadores recientes. Sostiene Yosef Kaplan que "cabe dudar si fue exactamente así [conforme afirma Révah] como sucedieron las cosas. No se puede asumir que el intelectualmente circunspecto Spinoza hubiera cambiado repentinamente su piel como resultado de la influencia de alguien que, aunque [como sugieren todos los datos] fuera también una figura carismática... era, en cuanto al poder intelectual, inferior a Spinoza. Es difícil suponer que en la época de su encuentro con Prado la mente de Spinoza fuera una

Spinoza realiza una ofrenda de 5 florines para los "pobres de Brasil" -es decir los sefaraditas repatriados de América luego de la pérdida colonial en Pernambuco.

${ }^{23}$ Gabriel Albiac, La sinagoga vacía: un estudio de las fuentes marranas del espinosismo, Hiperión, Madrid, 1987, pp.492-95.

${ }^{24}$ Des marranes a Spinoza, cit., pp. 197-206. 
tabla rasa"25. En sintonía con esta posición, Yirmiahu Yovel afirma que “...Prado y Spinoza llegaron a sus ideas heréticas independientemente y su encuentro simplemente contribuyó a galvanizarlas. Resulta difícil decir quién de los dos tuvo mayor influencia..."26. Y más radicalmente, Wim Klever invierte la tesis de Révah y afirma la tesis “Spinoza 'corruptor' de Prado". Sin negar un vínculo con Prado, afirma que la filiación fundamental de Spinoza es con Van den Enden. Argumenta a partir de 4 fuentes: Noticias de Colerus y Lucas que habrían sido descuidadas por Révah; datos del Diario de O. Broch, quien califica a Van den Enden y sus discípulos (Spinoza, Glazemaker...) de "cartesianos ateos"; testimonios de alumnos de Van den Enden y diversos escritores holandeses que afirman que Spinoza tomó su ateísmo de su maestro de latín; y la posibilidad -en base a estudios filológicos de O. Proietti- de que Spinoza haya escrito el TIE en torno a 1657. Por lo demás, la tesis de que Spinoza sería el "corruptor" de Prado tiene según Klever una primera apoyatura en la lectura atenta de la Epistola invectiva misma (de la que Kaplan ha identificado la existencia de al menos 15 copias) $)^{27}$.

El significado histórico-filosófico de la excomunión de Spinoza, sin embargo, no se agota en el estudio del sistema de vínculos que pudieron haber motivado algunas de sus opciones, ni puede ser totalmente explicado por las corrientes de pensamiento en las que se hallaba inscripta su radicalidad filosófica. Con toda probabilidad, antes de recurrir a la herramienta disciplinaria del herem, las autoridades religiosas ofrecieron al filósofo diversas alternativas para evitar el escándalo -incluso dinero para instalarse fuera de la ciudad y conservar las apariencias, como se sabe que sucedió en otros casos. Muy probablemente fue el propio Spinoza el que bloqueó cualquier alternativa que no fuera su excomunión, con una intransigencia que no le dejó a los rabinos otra posibilidad que el anatema. Se trató de una deliberada ruptura con la religión de sus padres, motivada por una precoz convicción universalista y el deseo de una forma de vida más allá de

\footnotetext{
${ }^{25}$ Yosef Kaplan, Fron Christianity to Judaism. The story of Isaac Orobio de Castro, Oxford University Press, 1989, pp 131-132.

${ }^{26}$ Yirmiahu Yovel, Spinoza and others heretics, Princeton University Press, 1989, I, p. 80.

${ }^{27}$ Wim Klever, "Spinoza 'corruptor de Prado o la teoría de Gebhardt y Révah invertida", en Spinoza y España, UCLM, 1994, pp. 217-27.
} 
cualquier particularidad, para llevar una existencia -en sentido fuerte- filosófica. El suyo no fue tanto un caso de persecución como de una disidencia, mantenida hasta el extremo. Spinoza, en efecto, no es el filósofo que rompe sino simplemente el filósofo que se va ("el que abandona su silla", según la etimología de disidente).

No era común en el siglo XVII -más aún, no consta ningún otro casoabandonar una religión para no entrar a ninguna otra, para ser solo un ciudadano en sentido puramente político $-\mathrm{y}$, en efecto, resulta significativo que el único libro publicado en vida bajo su nombre lleva la siguiente firma: Benedictum de Spinoza, Amstelodamensem, "ciudadano de Ámsterdam". Se abre con Spinoza una historia trágica, la historia del judaísmo moderno, signada por el drama de la asimilación y su imposibilidad ${ }^{28}$; un drama que tendrá su hora más aciaga en el siglo XX europeo y que involucra a nombres como los de Aby Warburg, Hannah Arendt o Sigmund Freud quien en cierta ocasión, tomando una expresión de Heine, se refirió de manera indirecta a Spinoza como "un compañero en la falta de fe" (Unglaubensgenossen).

Si el legado de Spinoza sigue vivo aún -y esperemos que así sea, pues la alternativa es la guerra infinita- no es otro que la construcción de una "comunidad de los sin comunidad", una comunidad de la que nadie está excluido por principio, origen u herencia -ni tampoco por abjurar de ellos. O dicho de manera más simple, el gran legado de Spinoza es la democracia -que en sus textos, sobre todo en ellos, es una palabra encantada todavía por pensar.

En efecto, hay un vínculo por desentrañar entre excomunión y democracia, en un sentido doble: en primer término -según han sugerido Steven Nadler y Lewis Samuel Feuer ${ }^{29}$ las ideas democráticas no estarían ausentes de las motivaciones que condujeron a la excomunión acaecida el 27 de julio de 1656; pero sobre todo, en segundo término -es lo que quisiera proponer aquí-, la experiencia de la excomunión del joven Baruch prospera en una filosofía de la democracia como producción de

\footnotetext{
${ }^{28}$ Sobre esta discusión, cfr. el epílogo ("Spinoza y su pueblo: ¿el primer judío secular?") de la primera parte del libro de Yirmiahu Yovel, Spinoza, el marrano de la razón, Anaya \& Mario Muchnik, Barcelona, 1995, pp. 183-212.

${ }^{29}$ Steven Nadler, cit., p. 208.
} 
comunidad -como producción común, de lo común- que Spinoza desarrolla desde entonces hasta su último escrito inconcluso. El legado político mayor es lo que esa palabra -democracia- atesora para nosotros como efecto de una ontología de la inclusión, de la expresión y de la común pluralidad.

Democracia nombra aquí un realismo emancipatorio de las fuerzas que realiza lo común absoluto en comunidades restrictas, cuyo surgimiento y expansión no se producen sin la resistencia de lo que las mantenía en clausura y sin la adversidad de la dominación. Lo común absoluto no es algo en sentido estricto sino lo que permite la irrupción, una y otra vez, de nuevas comunidades por obra de nociones comunes, de pasiones comunes y de acciones comunes. Tal vez pueda aún mantenerse la palabra "comunismo" como nombre de esa comunidad abierta, por realizar, desconocida, que revierte la identidad de lo propio - en tanto algo a lo que ya se pertenece y de lo que, por consiguiente, es posible poner-fuera, expulsar, excomulgar. La ontología spinozista de la necesidad es al mismo tiempo una filosofía de la novedad, por cuanto la potencia de la vida humana colectiva se confunde con la imaginación que produce el "mundo" tal y como es inmediatamente dado -en el sentido althusseriano que considera el "primer género de conocimiento" como revelación del mundo-, y también tal como no lo es, como lo que no es. Necesaria y creativa, la imaginación es potencia democrática en obra, tanto cuando se manifiesta como fuerza material como cuando es "explícita y lúcida”.

El spinozismo establece una perspectiva política desviada de la idea clásica de Buen Gobierno en tanto gobierno de la virtud, a la vez que con comprensión tradicional de la política producción de orden y supresión de conflictos; según ha sido más extensamente desarrollado en otra parte ${ }^{30}$, la condición civil no es la puesta en marcha de un artificio contra natura que vacía al cuerpo social de su derecho natural, sino que somete a ese mismo derecho a una extensión, una radicalización, una composición y una colectivización. El derecho público, por tanto, no suspende al derecho natural

\footnotetext{
${ }^{30}$ Ver Diego Tatián, Spinoza disidente, Tinta Limón, Buenos Aires, 2019, pp. 71 y ss.
} 
sino que lo politiza e incrementa. El derecho natural solo su vuelve concreto como "potencia de la multitud".

En tanto condición de permanencia y estabilidad de un Estado, la libertad spinozista no admite ser sacrificada a la seguridad; produce comunidad sin exigir de los seres humanos nada que vaya contra su naturaleza: no conmina a abjurar de sus ideas, ni a ser desapasionados, ni fuerza su conversión en ciudadanos puramente racionales y virtuosos. Antes bien, genera las condiciones materiales que permiten la autoinstitución política de la potencia común. El nombre spinozista de esa "República libre" es democracia. Con este término no se designa un mero conjunto de formas y procedimientos sino un desbloqueo que permite la manifestación efectiva de novedad y la liberación de una fuerza productiva de significados, instituciones y mediaciones de las que obtiene su vitalidad e impulsan el descubrimiento de lo común cuya interrogación se halla en el centro mismo del spinozismo, y lo vuelven un legado "tan difícil como raro"-.

Asimismo, con Spinoza es posible pensar una política emancipatoria no sometida a la idea del "hombre nuevo", a la idea de que los seres humanos debieran ser diferentes de como realmente son; por el contrario, lo que los seres humanos son capaces de ser y de hacer es siempre la revelación de un trabajo paciente y sin garantías que se mantiene en la inmanencia de su existir como seres naturales, apasionados y finitos. Un trabajo que cada generación deberá emprender una y otra vez porque no hay un sentido de la historia, ni la humanidad que ha tenido lugar puede ser reducida a una prehistoria de sí misma, ni existe un curso unitario de acontecimientos que lleve por necesidad a una reconciliación de los seres humanos consigo mismos.

Ante todo, una política spinozista no deja lugar a ningún lamento por la adversidad de las cosas -ni siquiera cuando, como es el caso de ser puesto fuera de una comunidad, esa adversidad es extrema-, ni promueve una ruptura reaccionaria con las situaciones concretas desde un moralismo que se arroga la función de juzgar los avatares de la vida colectiva a partir de una presunta sociedad ideal -perdida o por venir-; una política spinozista, más bien, es potenciación de los embriones 
emancipatorios que toda sociedad aloja en su interior para su extensión cuantitativa y cualitativa. Una confianza en lo que efectivamente hay (siempre algo bay) como punto de partida de la acción política.

El spinozismo alienta asimismo una responsabilidad por el estado, por sus fragilidades, por sus condiciones de estabilidad y los riesgos a los que se halla expuesto -cuando ese estado se constituye como "lugar común" y como precipitado de una potencia instituyente. Por ello la contribución de Spinoza en relación con algunas experiencias sociales y políticas recientes en América Latina es mucha. En particular la necesidad de concebir la democracia como contrapoder que puede tener en el estado su expresión y no necesariamente su bloqueo -siempre que la distancia entre el poder constituyente y las instituciones por él producidas sea mínima.

No sabemos lo que puede un cuerpo colectivo. Este es el punto de partida de una política emancipatoria, que lleva el nombre de democracia, si la entendemos como algo más que como pura vigencia de la ley y de los procedimientos (sin duda imprescindibles), si la concebimos también como "salvaje" (la expresión "democracia salvaje" es de Claude Lefort), es decir continua irrupción de derechos que provienen de un fondo irrepresentable y no previsto por las formas institucionales establecidas.

Democracia es así la existencia colectiva que tiene su inscripción en una excedencia del derecho concebido como potencia (fondo inagotable de la vida humana y por tanto inmanente a ella) respecto de la ley, que como tal es negativa y limita al derecho natural pero también puede convertirse en su expresión, en su protección y ser hospitalaria con novedades que se gestan en la fragua anómica de la imaginación y de la vida común. Democracia es comunidad de lo múltiple en tanto múltiple, comunidad del conflicto, excedencia de lo común absoluto respecto de cualquier forma constituida a través de la que se expresa. Por ello, en sentido spinozista democracia es la forma de vida colectiva que por principio no admite excomunión, sino más bien se vuelve plena como estallido de las disidencias.

Bajo una inscripción que podría animar las militancias libertarias de todos los tiempos -"no ridiculizar, ni lamentar ni detestar las acciones humanas, sino 
entenderlas"-, Spinoza ayuda a pensar el enigma democrático conforme un realismo radical que no supone exigencias sacrificiales, y que atesora una potencia común ejercida como afirmación pública y resistencia a los poderes que acechan la vida humana con su carga de superstición y de tristeza. La democracia spinozista está lejos de ser una pura tolerancia indiferente: es potencia ejercida, disidencia en acto, virtud (en el sentido estricto de vir, fuerza, que resuena en la palabra maquiaveliana virtù).

El deseo, por tanto, es un componente democrático fundamental de la vida republicana, cuando se abre a tensiones que pueden ser de gran fecundidad. No hay contradicción entre democracia y república (palabra esta última apropiada por las derechas latinoamericanas, que es necesario disputar y concebir a la manera antigua, desmarcándola de su reducción a una mera máquina procedimental de impedir transformaciones, para su determinación como conflicto del que nace la libertad); más bien la democracia debe hacerse republicana y la república volverse democrática.

En el siglo XVII, tanto como ahora, el enigma de la dominación nos confronta a dispositivos de sumisión que separan a los seres humanos de lo que pueden, inhiben su potencia política y capturan su imaginación en la tristeza y la "melancolía" -pasión antipolítica extrema que afecta la totalidad de un cuerpo. Lo que hoy llamamos "apatía" para referirnos a cierto retiro de lo público y a cierta pasividad civil sería pensado por Spinoza como una melancolía social -cuya hegemonía designaba con la expresión "estado de soledad".

Lo contrario es la bilaritas, palabra de difícil traducción que refiere la alegría integral que un cuerpo alcanza cuando se halla en plena posesión de su potencia de afectar. Tal vez sea posible interrogarnos qué sería una bilaritas colectiva. En mi opinión podría ser pensada como un ejercicio pleno y extenso de los derechos; la capacidad productiva de derechos nuevos e imprevistos; la alegría común de un sujeto complejo que se experimenta como causa de efectos emancipatorios; una determinación social del deseo como deseo de otros y no ya deseo de soledad.

Si en el siglo XVII excomunión significa en concreto condena a la soledad (“...nadie puede hablarle oralmente ni por escrito, ni hacerle ningún favor, ni estar con él 
bajo el mismo techo ni a menos de cuatro codos de él, ni leer papel hecho o escrito por ép’31), Spinoza deja en herencia una aventura existencial -su ética concreta- y una ofrenda conceptual que renueva su actualidad en el curso de las generaciones para reemprender un trabajo, filosófico y político, con las formas históricas de la soledad -con las Soledades: construir comunidad.

\section{Referencias}

-Albiac, Gabriel, La sinagoga vacía: un estudio de las fuentes marranas del espinosismo, Hiperión, Madrid, 1987.

-De Vries, Theun, Baruch Spinoza. Mil Selbstzengnissen und Bilddokumenten, Rowoblt, Hamburg, 1970.

-Domínguez, Atilano (comp.), Biografías de Spinoza, Alianza, Madrid, 1995.

-Dujovne, León, Spinoza, 4 vol., Universidad de Buenos Aires, 1940-1944.

-Francès, Madeleine, Spinoza dans les pays néerlandais de la seconde moitié du XVIle siècle, Alcan, Paris, 1937.

-Israel, Menasseh, Esperanza de Israel, edición de Henry Méchoulan y Gérard Nabon, Hiperión, Madrid, 1987.

-Kaplan, Yosef, Judios nuevos en Ámsterdam, Gedisa, Barcelona, 1996, pp.57-60.

----From Christianity to Judaism. The story of Isaac Orobio de Castro, Oxford University Press, 1989.

-Klever, Wim, "Spinoza 'corruptor de Prado o la teoría de Gebhardt y Révah invertida”, en Spinoza y España, UCLM, 1994.

-Méchoulan, Henri, “Le herem à Ámsterdam et 'l’excommunication' de Spinoza”, en Cabiers Spinoza, 3, Réplique, Paris, 1979-80.

-Meinsma, Koenraad, Spinoza et son cercle, Vrin, Paris, 1983.

-Nadler, Steven, Spinoza, Acento, Madrid, 2004.

${ }^{31}$ Atilano Domínguez (comp.), op. cit., p. 187. 
-Pineda Buitrago, Sebastián, "Baruch Spinoza y América Ladina: En busca del fraile colombiano 'delator' de Spinoza y del factor hispánico en el origen de la filosofía moderna” [http:// mww istor.cide.edu/archivos/num_42/notas.pd]].

-Popkin, Richard, “The Marrano Theology of Isaac La Peyrère”, en Studi Internazionali di Filosofia, $\mathrm{n}^{\circ}$ 5, 1973.

---------------Isaac La Peyrère, 1596-1676, Brill, Leiden, 1987.

-Révah, Israel, Des marranes a Spinoza, textos reunidos por Henri Mechoulan, PierreFrançois Moreau y Carsten Lorenz Wilke, Vrin, Paris, 1995.

-Segond, Jules, La vie de Benồt de Spinoz̧a, Librairie Académique Perrin Éditeur, Paris, 1933.

-Tatián, Diego, Spinoza disidente, Tinta Limón, Buenos Aires, 2019.

-Teicher, Jacob, "Why was Spinoza banned?", in The Menorah Journal, vol. XI, V (1957).

-Vaz Dias, A. M. y Van der Tak, W. G., Spinoza, mercator et autodidactus, Martinus Nijhoff, Den Haag, 1933.

-Yovel, Yirmiahu, Spinoza and others heretics, Princeton University Press, 1989.

--------------Spinoza, el marrano de la razón, Anaya \& Mario Muchnik, Barcelona, 1995.

-Ze'ev, Levy, "Sur quelques influences juives dans le developpement philosophique du jeune Spinoza”, en Revue des Sciences philosophiques et théologiques, 71, 1/1987.

RECIBIDO: $24 / 04 / 2020$

APROBADO: 02/06/2020

RECEIVED: 04/24/2020

APPROVED: 06/02/2020 